\title{
Distribuição Volumétrica e Diâmetro de Gotas de Pontas de Pulverização de Energia Hidráulica para Controle de CORDA-DE-VIOLA ${ }^{1}$
}

\author{
Volumetric Distribution and Droplet Size of Hydraulic Spraying Nozzles for the Control of Scarlet \\ Morningglory
}

FERREIRA, M.C. ${ }^{2}$, LOHMANN, T.R. ${ }^{3}$, CAMPOS, A.P. ${ }^{3}$, VIEL, S.R. ${ }^{3}$ e FIGUEIREDO, A. ${ }^{3}$

\begin{abstract}
RESUMO - As pontas de pulverização são responsáveis pela formação das gotas, e cada ponta apresenta características próprias relacionadas ao espectro de gotas e perfil de deposição, específicas para determinados alvos. Este trabalho teve o objetivo de caracterizar o diâmetro e a uniformidade das gotas e o perfil de distribuição volumétrica das pontas de pulverização AI 110015 e TTI 110015, bem como seu efeito sobre a mortalidade de corda-de-viola, com herbicida pré-emergente, associado ou não a adjuvantes. Avaliou-se o número de plantas emergidas e os pesos secos da parte aérea e radicular das plantas. Os perfis de distribuição volumétrica para a altura de $40 \mathrm{~cm}$ foram avaliados em mesa de deposição. A partir dos perfis de distribuição, simulou-se o padrão de deposição ao longo da barra de pulverização. $O$ espectro do diâmetro de gotas foi determinado em analisador de tamanho de partículas por difração de luz laser. O herbicida diuron + hexazinona foi eficiente no controle em préemergência de corda-de-viola, podendo ser utilizado polimetil siloxano organomodificado ou óleo mineral como adjuvantes, associados às pontas de pulverização AI 110015 ou TTI 110015. O uso de adjuvantes proporcionou aumento no diâmetro mediano volumétrico e redução na porcentagem de gotas com diâmetro inferior a $100 \mu \mathrm{m}$. O espaçamento sugerido entre os bicos na barra de pulverização foi de $70 \mathrm{~cm}$ para o modelo AI 110015 e $80 \mathrm{~cm}$ para o modelo TTI 110015.
\end{abstract}

Palavras-chave: padrão de deposição, tecnologia de aplicação, Ipomoea hederifolia .

\begin{abstract}
Nozzles are responsible for the formation of drops, with each side presenting its own characteristics related to droplet deposition spectrum and profile specific to certain targets. This study aimed to characterize the diameter and uniformity of the droplets and volumetric distribution profile of nozzles AI 110015 and 110015 TTI, as well as their effect on the mortality of scarlet morningglory, using pre-emergent herbicide, alone or combined with adjuvants. The number of emerging plants and dry weight of shoot and root growth were evaluated. Volumetric distribution profiles for a $40 \mathrm{~cm}$ height were evaluated in a table deposition. Based on the distribution profiles, a deposition pattern was simulated along the spray boom. Droplet diameter spectrum was determined in a particle size analyzer by laser light diffraction. The herbicide mixture diuron thexazinone was effective in controlling pre-emergence scarlet morningglory, and organo-modified polymethyl siloxane or mineral oil may be used as adjuvants, in association with nozzles AI 110015 or 110015 TTI. The use of adjuvants allowed the increase in volume median diameter and reduction in the percentage of droplets with diameter below 100 micrometers. The suggested spacing between nozzles on the spray bar was $70 \mathrm{~cm}$ for AI 110015 and $80 \mathrm{~cm}$ for the TTI 110015.
\end{abstract}

Keywords: deposition pattern, application technology, Ipomoea hederifolia.

1 Recebido para publicação em 14.9.2010 e aprovado em 4.2.2011.

2 Professor, Dr., Adjunto do Dep. de Fitossanidade da Universidade Estadual Paulista Júlio de Mesquita Filho - UNESP, 14.884-900 Campus Jaboticabal, <mdacosta@fcav.unesp.br>; ${ }^{3}$ Pós-Graduando do Dep. de Fitossanidade, UNESP, Campus Jaboticabal.

Planta Daninha, Viçosa-MG, v. 29, n. 3, p. 697-705, 2011 


\section{INTRODUÇÃO}

A contaminação ambiental pelo uso de produtos fitossanitários gera preocupações quanto à utilização inadequada desses compostos. A crescente demanda da sociedade civil, de órgãos legisladores e fiscalizadores por processos produtivos com menor impacto ambiental remete à necessidade de se avaliar o comportamento e destino dessas substâncias usadas nos agroecossistemas (Luchini \& Andréa, 2000).

A deriva é uma das principais formas de perda de produtos fitossanitários e, consequentemente, de contaminação ambiental. De acordo com Matuo (1990), deriva é tudo aquilo que não atinge o alvo durante a aplicação. A perda na forma de vapor pode ocorrer durante ou posteriormente à aplicação, sendo muito dependente da pressão de vapor e das características da formulação do produto.

Assim, a tecnologia de aplicação de produtos fitossanitários é fator-chave para se realizar a aplicação sem desperdícios, de tal forma que faça com que o produto atinja o alvo. As aplicações podem, muitas vezes, produzir o efeito desejado, porém de forma ineficiente, pela não utilização da técnica ou equipamento mais adequado. Caso se utilize da técnica ou equipamento adequados, poder-se-ia diminuir a quantidade de ingrediente ativo lançada no ambiente (Cunha et al., 2004). Estima-se que cerca de $50 \%$ dos produtos fitossanitários sejam desperdiçados devido às más condições de aplicação (Friedrich, 2004).

A adoção de técnicas corretas de aplicação pode efetivamente reduzir o risco ou a quantidade de deriva produzida nas aplicações de produtos fitossanitários. A seleção de pontas de pulverização e adjuvantes adequados pode ser uma medida eficiente para reduzir a deriva, pela produção de gotas de maior diâmetro, menos sujeitas à deriva (Costa et al., 2007; Queiroz et al., 2008).

As pontas de pulverização são responsáveis pela formação das gotas e, por isso, determinantes no processo de pulverização e diminuição da deriva. As funções das pontas compreendem a fragmentação do líquido em pequenas gotas, distribuição das gotas em determinada área e controle da saída de líquido por unidade de área (Sidahmed, 1998). De acordo com Butler Ellis et al. (2002), pontas com de indução de ar tornaram-se a tecnologia mais comum para evitar a deriva, pois formam gotas que contêm ar dentro de si e, assim, aumentam o tamanho delas, uma vez que gotas muito pequenas são mais suscetíveis à deriva.

Segundo Viana et al. (2010), os parâmetros de maior importância para a determinação da população de gotas são o diâmetro da mediana volumétrica (DMV), a amplitude relativa (AR) e a porcentagem de gotas com diâmetro inferior a $100 \mu \mathrm{m}$. Em conjunto, definem o potencial de deriva da pulverização, a homogeneidade e o tamanho das gotas produzidas pelas pontas de pulverização.

Outra característica importante na tecnologia de aplicação é a uniformidade de distribuição. Segundo Bauer \& Raetano (2004), a uniformidade de distribuição está diretamente relacionada com o espaçamento entre pontas, a pressão de trabalho, a altura da barra em relação ao alvo e o ângulo de abertura do jato das pontas de pulverização e serve como referência para verificar a distribuição do ingrediente ativo no alvo. É aferida pelo coeficiente de variação da sobreposição da deposição de um conjunto de pontas numa barra de pulverização.

Diante do exposto, o objetivo deste trabalho foi caracterizar o diâmetro e a uniformidade das gotas e o perfil de distribuição volumétrica das pontas de pulverização AI 110015 e TTI 110015, considerando diferentes caldas, com ou sem adição de adjuvantes, bem como o efeito da pulverização de um herbicida pré-emergente, utilizando essas duas pontas sobre a emergência de corda-de-viola (Ipomoea hederifolia), em associação ou não com adjuvantes.

\section{MATERIAL E MÉTODOS}

\section{Controle de Ipomoea hederifolia com diferentes caldas e pontas de pulverização}

Semeou-se I. hederifolia em vasos com volume de cinco litros, contendo duas partes de solo e uma parte de esterco bovino. O delineamento experimental foi inteiramente 
casualizado, em esquema fatorial 3 (caldas herbicidas) x 2 (pontas de pulverização) +1 testemunha, com quatro repetições, constituindo sete tratamentos ao todo. Os tratamentos consistiram de três caldas de herbicida com diuron + hexazinona (Dizone $\left.{ }^{\circledR}\right)\left(200 \mathrm{~L} \mathrm{ha}^{-1}\right)$; diuron + hexazinona $\left(\right.$ Dizone $\left.^{\circledR}\right)+$ polimetil siloxano organomodificado $\left(\right.$ Silwett $\left.^{\circledR}\right)(0,1 \%$ $\mathrm{v} / \mathrm{v}$ ) e diuron + hexazinona (Dizone $\left.{ }^{\circledR}\right)+$ óleo mineral (Oppa BR $\left.{ }^{\circledR}\right)(1 \% \mathrm{v} / \mathrm{v})$, com duas pontas de pulverização, modelos AI 110015 e TTI 110015 , e uma testemunha sem pulverização.

A aplicação dos tratamentos foi realizada em pré-emergência da planta daninha, com equipamento de pulverização costal pressurizado a $\mathrm{CO}_{2}$ em pressão de trabalho constante de $40 \mathrm{lbf} \mathrm{pol}^{-2}$. A barra de pulverização foi constituída por pontas AI 110015 ou TTI 110015, espaçadas de $50 \mathrm{~cm}$.

Avaliou-se o número de plantas emergidas aos 14 dias após a pulverização (DAP); aos 21 DAP foram coletadas as plantas para obter o peso da parte aérea seca e de raízes. $O$ material vegetal obtido foi colocado em sacos de papel e mantido por 96 horas em estufa de secagem forçada a $60{ }^{\circ} \mathrm{C}$.

Os dados foram submetidos à análise de variância pelo teste $\mathrm{F}$, e as médias, comparadas pelo teste de Tukey a $5 \%$ de probabilidade.

\section{Determinação do diâmetro e uniformidade das gotas}

O espectro de gotas produzido pelas pontas AI 110015 e TTI 110015 foi determinado com analisador de diâmetro de partículas por difração de raios laser (Mastersizer $\mathbf{S}^{\circledR}$ versão 2.19). Nesse equipamento, uma unidade óptica determina o diâmetro das gotas do espectro pulverizado, por meio do desvio de trajetória sofrido pelo laser ao atingi-las. Quanto menor a partícula, maior é o grau de difração que o raio de luz sofre (Etheridge et al., 1999).

Conforme recomendações do fabricante, o equipamento foi ajustado para avaliar gotas de 0,5 a $900 \mathrm{~mm}$ (lente de $300 \mathrm{~mm}$ ). Um exaustor (tipo coifa) localizado sobre o equipamento onde é pulverizado o jato retira as partículas que ficam suspensas no ar, que poderiam resultar em duplas leituras ou se depositar sobre a lente do aparelho, comprometendo a exatidão da análise.

A pulverização foi acionada com ar comprimido, através de $\mathrm{CO}_{2}$, e a pressão, mantida constante com auxílio de um regulador de pressão de precisão. Utilizou-se de oscilador para que o jato de calda atravessasse transversalmente o laser durante a leitura pelo aparelho. O tempo despendido pelo oscilador para mover-se de um extremo ao outro do jato aplicado foi calibrado para 3 segundos. Cada leitura do laser foi realizada com intervalo de 2 milissegundos, totalizando 500 leituras por segundo.

Foram realizadas quatro repetições da leitura para as caldas de pulverização, e duas repetições para as pontas avaliadas. Determinaram-se os parâmetros: diâmetro mediano volumétrico (DMV), uniformidade do espectro de gotas (coef.) e porcentagem do volume aplicado, das gotas com diâmetro inferior a $100 \mu \mathrm{m}(\% \mathrm{~V}<100 \mu \mathrm{m})$.

Os resultados de DMV, coef. e \%V $<100 \mu \mathrm{m}$ produzidos pelos modelos AI 110015 e TTI 110015 nas três caldas pulverizadas foram submetidos à análise de variância pelo teste $\mathrm{F}$, e as médias, comparadas pelo teste de Tukey a $5 \%$ de probabilidade.

\section{Distribuição volumétrica e determinação do espaçamento entre bicos}

A avaliação do perfil de distribuição volumétrica foi realizada em mesa de deposição composta por uma chapa de metal corrugada, formando 67 canaletas em V, separadas de $2,5 \mathrm{~cm}$ entre si, totalizando $167,5 \mathrm{~cm}$ de largura. Na parte inferior da mesa de deposição foram colocados tubos de ensaio de $100 \mathrm{~mL}$ para coleta da calda pulverizada, sendo um tubo para cada canaleta.

A ponta de pulverização foi posicionada no centro da mesa, de modo que o jato fosse lançado na posição vertical, com $40 \mathrm{~cm}$ de altura, segundo recomendações da FAO (1998). O perfil de distribuição volumétrica foi avaliado para as três caldas e as duas pontas de pulverização, na pressão de trabalho de $40 \mathrm{lbf} \mathrm{pol}^{-2}$, onde o ângulo de abertura do jato foi mensurado por meio de um goniômetro analógico.

Planta Daninha, Viçosa-MG, v. 29, n. 3, p. 697-705, 2011 
A pulverização foi realizada até que os tubos de ensaio das canaletas centrais (que recebem maior quantidade de calda) atingissem $90 \%$ do limite máximo de volume. Em seguida, registrou-se o volume de calda contido em cada tubo de ensaio. O perfil de distribuição volumétrica foi determinado com base na média dos volumes coletados nas duas repetições para cada calda e pontas de pulverização. O perfil de distribuição volumétrica obtido foi usado para determinar, em planilha eletrônica (Microsoft Excel), os espaçamentos entre bicos a serem utilizados numa barra de pulverização.

A uniformidade de distribuição ao longo da faixa aplicada foi avaliada por meio do coeficiente de variação (FAO, 1998), sendo este aceitável para a uniformidade de distribuição de até $10 \%$. Assim, o espaçamento entre bicos na barra necessita se situar dentro desse limite. Estabeleceu-se a equação de regressão considerando a relação do espaçamento entre bicos e seus respectivos coeficientes de variação.

\section{RESULTADOS E DISCUSSÃO}

Para o número de plantas emergidas aos 14 DAP, verificou-se que os tratamentos foram eficientes no controle em pré-emergência de I. hederifolia em todas as situações estudadas, uma vez que houve diferença significativa entre a testemunha e a aplicação do herbicida diuron + hexazinona com ou sem adição de adjuvantes e com os diferentes modelos de ponta de pulverização, porém não entre os tratamentos (Figura 1).

Apesar de ocorrer emergência de algumas plantas nos tratamentos com herbicida, estas não se desenvolveram além do estádio de plântulas. Ao que tudo indica, quando iniciaram a absorção da solução coloidal do solo, entraram em contato com moléculas do herbicida, causando sua morte. Esse fato foi corroborado aos 21 dias após a aplicação dos herbicidas, quando se coletaram as plantas para se obter a massa seca da parte aérea e raízes. Nessa ocasião, não havia mais qualquer sinal das plantas que emergiram nos tratamentos com aplicação de herbicida e, portanto, os valores de massa seca nesses tratamentos são nulos. Os valores para peso seco obtidos na testemunha foram de $0,80 \mathrm{~g}$ para raízes e de 1,93 g para a parte aérea de I. hederifolia.

A uniformidade do espectro de gotas não foi alterada pelas diferentes caldas e modelos de pontas avaliadas (Tabela 1). Contudo, o diâmetro mediano volumétrico e a \%V $<100 \mu \mathrm{m}$ foram diferentes, de acordo com a calda e a ponta de pulverização.

O herbicida sem adjuvante apresentou menor DMV quando comparado às caldas com polimetil siloxano organomodificado ou óleo mineral. Portanto, a adição dos adjuvantes no

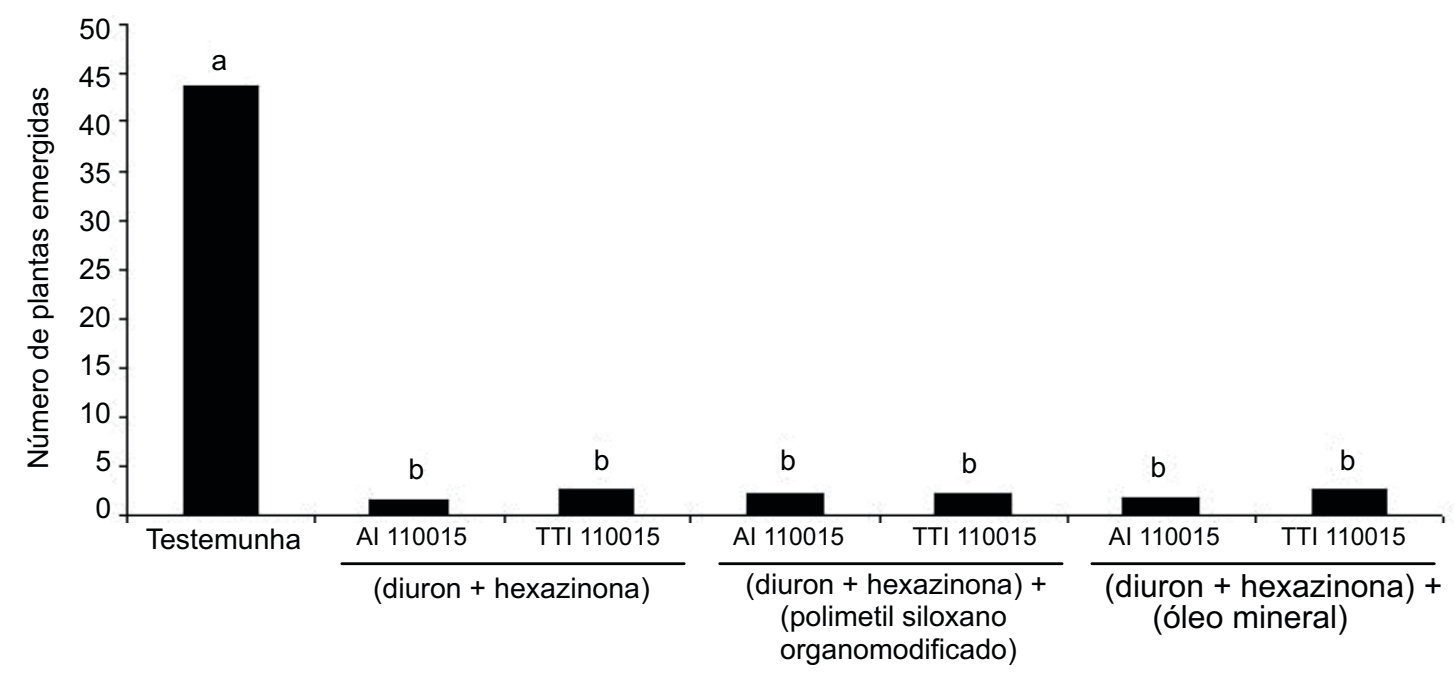

Figura 1 - Número de plantas emergidas (NPE) de Ipomoea hederifolia aos 14 dias após a pulverização (DAP) do herbicida diuron+hexazinona em pré-emergência, com diferentes adjuvantes e pontas de pulverização. 
Tabela 1 - Diâmetro mediano volumétrico (DMV), uniformidade do espectro de gotas (Coef.) e porcentagem do volume aplicado cujas gotas possuam diâmetro inferior a $100 \mu \mathrm{m}(\% \mathrm{~V}<100 \mu \mathrm{m})$ de diferentes caldas, pulverizadas com dois modelos de bicos (AI 110015 e TTI 110015)

\begin{tabular}{|c|c|c|c|}
\hline Fator & $\operatorname{DMV}(\mu \mathrm{m})^{1 /}$ & Coef. ${ }^{\prime /}$ & $\% \mathrm{~V}<100 \mu \mathrm{m}^{1}$ \\
\hline (diuron + hexazinona) & $544,12 \mathrm{~b}$ & $1,78 \mathrm{a}$ & $4,44 \mathrm{a}$ \\
\hline$($ diuron + hexazinona $)+($ polimetil siloxano organomodificado $)$ & $690,05 \mathrm{a}$ & $1,80 \mathrm{a}$ & $1,94 \mathrm{~b}$ \\
\hline$($ diuron + hexazinona $)+($ óleo mineral $)$ & $717,67 \mathrm{a}$ & $1,65 \mathrm{a}$ & $1,62 \mathrm{~b}$ \\
\hline AI 110015 & $612,40 \mathrm{~b}$ & $1,71 \mathrm{a}$ & $3,08 \mathrm{a}$ \\
\hline TTI 110015 & $688,82 \mathrm{a}$ & $1,77 \mathrm{a}$ & $2,25 \mathrm{~b}$ \\
\hline $\mathrm{CV}(\%)$ & 6,75 & 14,31 & 30,82 \\
\hline
\end{tabular}

${ }_{1 /} \mathrm{Na}$ coluna, para cada fator, médias seguidas das mesmas letras não diferem entre si pelo teste de Tukey a $5 \%$ de probabilidade.

presente trabalho proporcionou gotas com diâmetros maiores quando adicionados à calda de pulverização com o herbicida diuron + hexazinona. Thebaldi et al. (2009) e Cunha et al. (2003) também observaram aumento do DMV quando se adicionou um adjuvante à calda de pulverização. Todavia, esses dois trabalhos não especificam a calda de pulverização utilizada. Por outro lado, Stainier et al. (2006) observaram que a adição de Silwet L-77 ou óleo vegetal esterificado aumentou significativamente o DMV quando comparando apenas o tratamento água com o tratamento água mais adjuvante, mas não alterarou o DMV quando foi adicionado à calda do herbicida fenemedifame em duas formulações (suspensão concentrada e concentrado emulsionável), considerando três pontas de pulverização diferentes. Na prática, gotas maiores estão menos sujeitas a serem perdidas por deriva; assim, a adição de adjuvantes pode reduzir o potencial de deriva na pulverização de produtos fitossanitários (Queiroz et al., 2008).

Quando se observa o parâmetro \%V < $100 \mu \mathrm{m}$, verifica-se que no momento em que a calda é pulverizada na presença dos adjuvantes polimetil siloxano organomodificado e óleo mineral houve significativamente menor produção de gotas menores que $100 \mu \mathrm{m}$. A testemunha (diuron + hexazinona) apresentou $4,44 \%$ em volume de gotas com diâmetro inferior a $100 \mu \mathrm{m}$, enquanto os tratamentos com adição de óleo mineral e polimetil siloxano organomodificado apresentaram volumes de 1,62 e 1,94\%, respectivamente (Tabela 1).

Gotas com diâmetro menor que $100 \mu \mathrm{m}$ são mais suscetiveis à deriva, seja através do arraste pelo vento para fora da área de aplicação ou pela evaporação. Cunha et al. (2004) mencionam que gotas com diâmetro inferior a $100 \mu \mathrm{m}$ são as principais responsáveis pelo aumento no risco da deriva. Lefebvre (1989) refere-se a gotas de diâmetros próximos a $150 \mu \mathrm{m}$, que, além de serem arrastadas com facilidade pelo vento, são altamente suscetiveis à evaporação. Etheridge et al. (1999) são ainda mais rigorosos, afirmando que gotas abaixo de $200 \mu \mathrm{m}$ são as mais suscetiveis à deriva. Dessa forma, quanto menos gotas com essa característica forem produzidas pela pulverização, menor será o potencial de deriva.

Assim, a adição dos adjuvantes promoveu resultado positivo sobre as características das gotas, diminuindo o número de gotas com diâmetro menor que $100 \mu \mathrm{m}$ produzidas pela pulverização com diferentes modelos de pontas. Entretanto, como a classe de gotas produzidas pelas pontas de pulverização estudadas é pouco suscetível à deriva, a ação dos adjuvantes - embora tenham reduzido o volume em gotas menores que $100 \mu \mathrm{m}$ de $4,5 \%$ para menos de $2 \%$ - pode ser considerada mais importante no espalhamento das gotas sobre a superficie tratada, bem como em melhorias na qualidade da distribuição da calda, como será visto adiante (Queiroz et al., 2008).

Comparando os adjuvantes, não se observou diferença em relação às características das gotas produzidas pela pulverização. Assim, ambos podem ser considerados numa estratégia de diminuição do potencial de deriva, atuando sobre as características de gotas, não diferindo entre si quanto a esse aspecto. A diferença a ser observada quando se optar pelo uso deles estará na forma como se comportam e agem sobre as superficies foliares. 
No presente estudo, avaliaram-se dois modelos de pontas de pulverização com indução de ar, porém deve-se atentar para a importância da escolha correta da ponta de pulverização, uma vez que existem modelos com cerca de $30 \%$ de gotas menores que $100 \mu \mathrm{m}$. Normalmente são modelos sem indução de ar, como pode ser visto no trabalho de Stainier et al. (2006), em que modelos sem indução de ar variaram entre 10 e $40 \%$ de volume de gotas menores que $100 \mu \mathrm{m}$ e o modelo com indução de ar não ultrapassou 4\% em nenhuma situação avaliada. A mesma relação entre pontas com indução de ar e sem indução de ar pode igualmente ser observada no trabalho de Cunha et al. (2003). Assim, tratandose do herbicida dizone + hexazinone em préemergência, a escolha correta da ponta de pulverização deverá fazer mais diferença que a própria adição dos adjuvantes à calda.

A comparação entre as pontas de pulverização demonstra que o modelo TTI 110015 apresentou maior DMV e menor \%V $<100 \mu \mathrm{m}$ em relação ao AI 110015 (Tabela 1). Essa diferença pode ser atribuída às características inerentes às pontas; o modelo TTI (Turbo TeeJet ${ }^{\circledR}$ Induction), além de apresentar a mesma característica de indução de ar das pontas AI (Air Induction), também apresenta defletor, que possibilita produção de gotas maiores e maior ângulo de abertura numa mesma pressão de trabalho, em comparação com os modelos AI. Todavia, Viana et al. (2010) não observaram o mesmo comportamento para as pontas TTI 110015 e AI 110015 em relação ao DMV e $\% \mathrm{~V}<100 \mu \mathrm{m}$. Para esses autores, os dois modelos não diferiram entre si quando submetidos à pressão de $200 \mathrm{kPa}$ (a mais próxima de $40 \mathrm{lbf}^{\text {pol}^{-2}}$ das pressões avaliadas pelos autores). Esse resultado diferente talvez possa ser atribuído ao líquido pulverizado, que em Viana et al. (2010) foi apenas água.

Os valores observados para as pontas TTI 110015 e AI 110015 em relação ao percentual do volume de gotas com diâmetro menor que $100 \mu \mathrm{m}$, respectivamente de 2,25 e $3,08 \%$, são consideravelmente inferiores aos normalmente obtidos com pontas sem indução
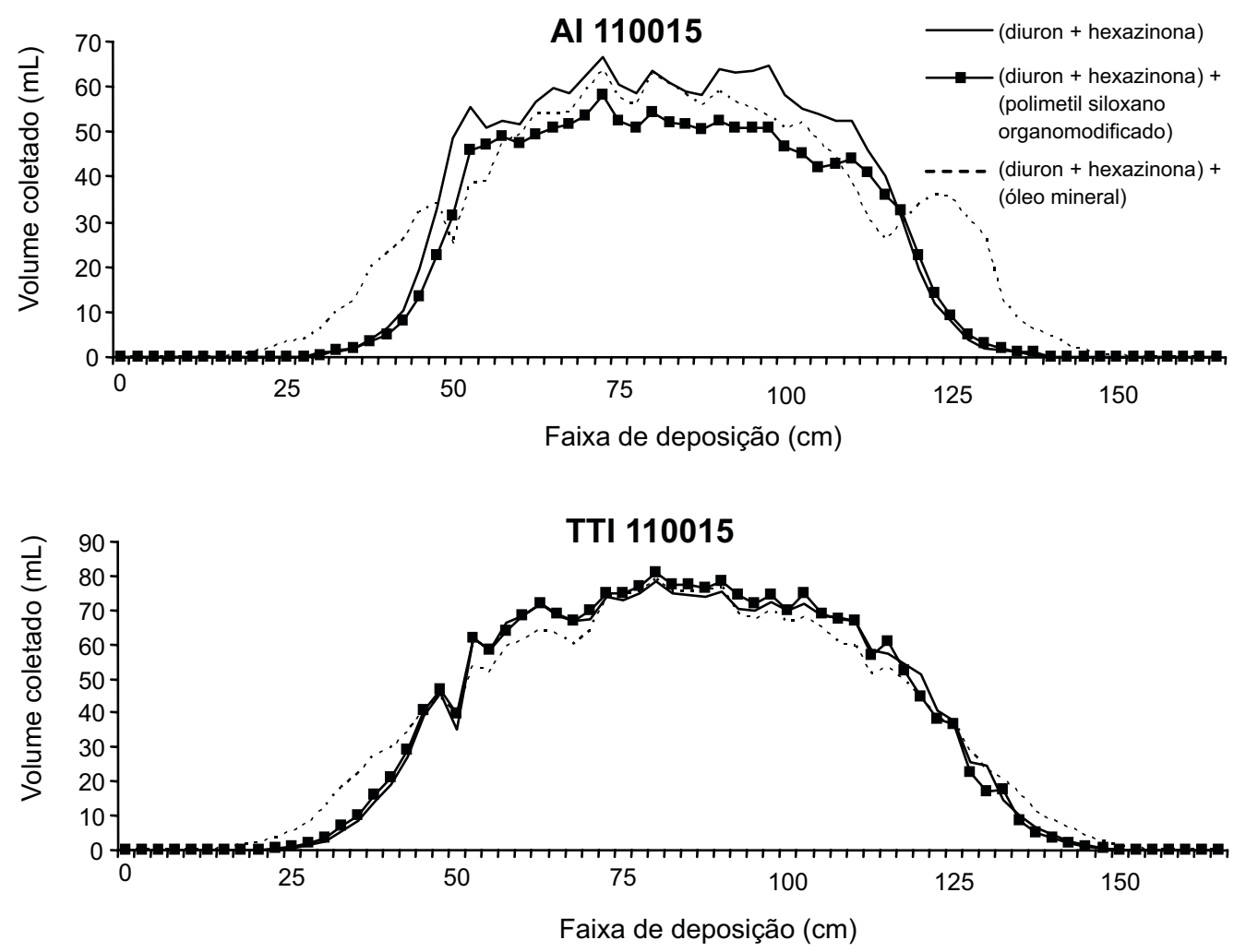

Figura 2 - Perfil de distribuição das pontas AI 110015 e TTI 110015 em mesa de deposição, considerando diferentes caldas pulverizadas. 
de ar, como pode ser observado no estudo de Cunha et al. (2007), onde os autores obtiveram valores superiores a $10 \%$ utilizando pontas de jato plano padrão (API 11002 e API 11004) e acima de $6 \%$ para a ponta antideriva com préorificio (ADI 11002). De acordo com Cunha et al. (2003), valores abaixo de $15 \%$ indicam maior segurança para as aplicações de produtos fitossanitários em relação ao risco de deriva, devido ao tamanho das gotas.

Quanto ao perfil de distribuição em mesa de deposição, verifica-se que o modelo AI 110015 apresenta maior volume no centro, com quedas bruscas nas extremidades, ao contrário do TTI 110015, que apresenta deposição mais bem distribuída, decrescendo do centro para as extremidades (Figura 2). Pontas com esse padrão de deposição são recomendadas para trabalhar em barras, havendo sobreposição entre elas (Matuo et al., 2001).

De acordo com as simulações de sobreposição de jato, sugere-se o uso do espaçamento máximo de 70 e $80 \mathrm{~cm}$ entre os bicos na barra de pulverização, respectivamente, para os modelos de pontas AI 110015 e
Al 110015 - (diuron + hexazinona)

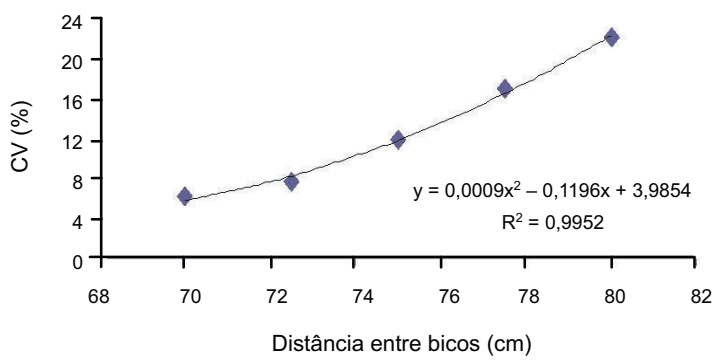

Al 110015 - (diuron + hexazinona) + (polimetil siloxano organomodificado)
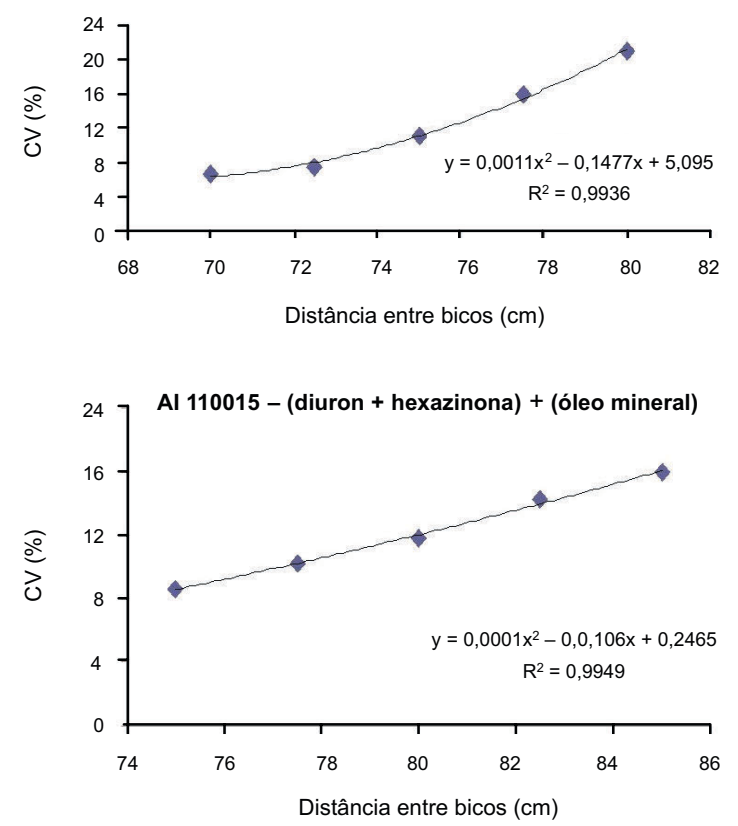

TTI 110015 - (diuron + hexazinona)

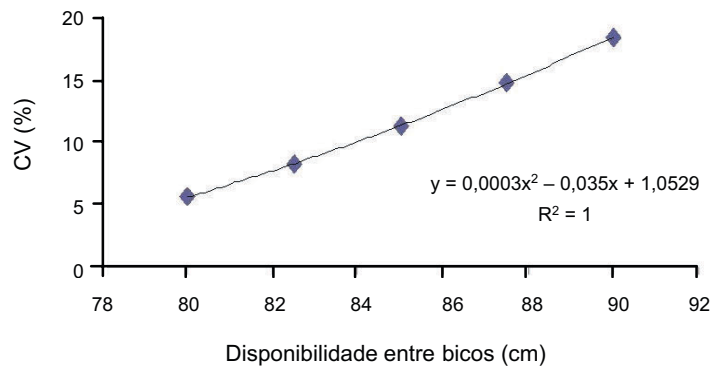

TTI 110015 - (diuron + hexazinona) + (polimetil siloxano organomodificado)

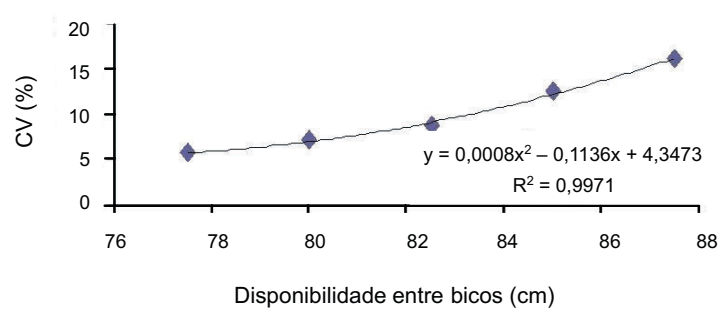

TTI 110015 - (diuron + hexazinona) + (óleo mineral)

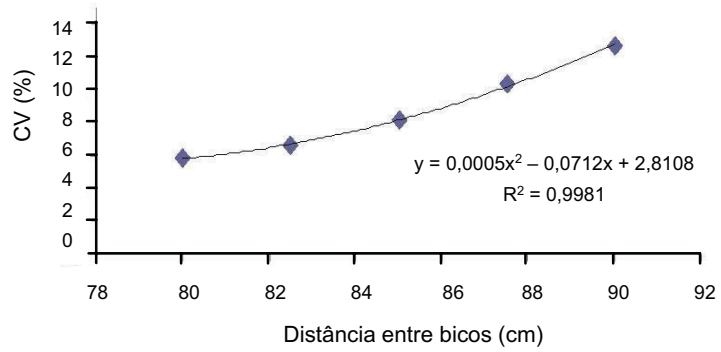

Figura 3 - Coeficiente de variação (CV) em função do espaçamento entre bicos na barra de pulverização. Sem adjuvante: herbicida (diuron + hexazinona); adjuvante A: (diuron + hexazinona) + (polimetil siloxano organomodificado); adjuvante B: (diuron + hexazinona $)+($ óleo mineral $)$ 
TTI 110015 (Figura 3). Esses espaçamentos são sugeridos, pois, de acordo com o perfil de distribuição individual da ponta em mesa de deposição, ao sobrepor os jatos, o coeficiente de variação do perfil de distribuição conjunto das pontas foi cerca de $6 \%$ para todas as situações avaliadas. Esse valor é aceitável, situando-se abaixo do valor-limite de $10 \%$ de variação no perfil, mantendo assim margem de segurança para os usuários, comumente recomendada por fabricantes (Fernandes et al., 2007).

Para o ângulo de abertura do jato, considerando a pressão de $40 \mathrm{lbf} \mathrm{pol}^{-2}$, verificou-se que a ponta TTI 110015 apresentou valores mais próximos ao ângulo nominal do modelo $\left(110^{\circ}\right)$, quando comparado ao modelo AI 110015. Para a ponta TTI 110015 e caldas com diuron + hexazinona, (diuron + hexazinona) + (polimetil siloxano organomodificado) e (diuron + hexazinona) + (óleo mineral), os valores observados do ângulo de abertura do jato foram de $111,5^{\circ}, 111^{\circ}$ e $112,5^{\circ}$, respectivamente, assim como de $98,5^{\circ}, 99,5^{\circ}$ e $104^{\circ}$, respectivamente, para o modelo AI 110015 . Esses resultados diferem dos obtidos por Ferreira et al. (2009), que não observaram diferença entre o ângulo nominal e o ângulo efetivamente obtido para os mesmos modelos de ponta. Para os dois modelos, observa-se que o óleo mineral proporcionou pequeno aumento no ângulo de abertura, estando isso provavelmente relacionado a mudanças nas características do líquido pulverizado, conforme já observado em outros trabalhos de pesquisa (Miller \& Butler Ellis, 2000).

Ambos os modelos de pontas de pulverização avaliados apresentaram baixo potencial de risco à deriva e controle satisfatório de corda-de-viola (I. hederifolia) com o herbicida utilizado. O uso de adjuvantes proporcionou ganho na qualidade do espectro de gotas, mas sem efeito no controle das plantas daninhas, sendo a sua indicação condicionada aos custos desses produtos e relacionada às condições meteorológicas durante as aplicações.

\section{LITERATURA CITADA}

BAUER, F. C.; RAETANO, C. G.. Distribuição volumétrica de calda produzida pelas pontas de pulverização XR, TP e TJ sob diferentes condições operacionais. Planta Daninha, v. 22, n. 2 , p. $275-284,2004$

Planta Daninha, Viçosa-MG, v. 29, n. 3, p. 697-705, 2011
BUTLER ELLIS, M. C. et al. Design factors affecting spray characteristics and drift performance of air induction nozzles. Biosyst. Eng., v. 82, n. 3, p. 289-296, 2002.

COSTA, A. G. F. et al. Efeito da intensidade do vento, da pressão e de pontas de pulverização na deriva de aplicações de herbicidas em pré-emergência. Planta Daninha, v. 25, n.1, p. 203-210, 2007.

CUNHA, J. P. A. R. et al. Avaliação de estratégias para redução da deriva de agrotóxicos em pulverizações hidráulicas Planta Daninha, v. 21, n. 2, p. 325-332, 2003.

CUNHA, J. P. A. R. et al. Avaliação do espectro de gotas de pontas de pulverização hidráulicas utilizando a técnica da difração do raio laser. Eng. Agríc., v. 27, n. spe., p. 10-15, 2007.

CUNHA, J. P. A. R. et al. Espectro de gotas de bicos de pulverização hidráulicos de jato plano e de jato cônico vazio. Pesq. Agropec. Bras., v. 39, n. 10, p. 977-85, 2004

ETHERIDGE, R. E. et al. Characterization of the spray droplet spectra and patterns of four venturi-type drift reduction nozzles. Weed Technol., v. 13, n. 4, p. 765-70, 1999.

FOOD AND AGRICULTURE ORGANIZATION OF THE UNITED NATIONS - FAO. Agricultural pesticide sprays Rome: 1998. v. 2. p. 62.

FERNANDES, A. P. et al. Caracterização do perfil de deposição e do diâmetro de gotas e otimização do espaçamento entre bicos na barra de pulverização. Eng. Agric., v. 27, n. 3, p. 728-33, 2007.

FERREIRA, M. C. et al. Distribuição da calda herbicida por pontas de pulverização agrícola utilizadas em áreas de reflorestamento com eucalipto. Eng. Agric., v. 29, n. 2, p. 267-276, 2009.

FRIEDRICH, T. Quality in pesticide application technology. In: RAETANO, C. G.; ANTUNIASSI, U. R. Qualidade em tecnologia de aplicação. Botucatu: Fepaf, 2004. p. 93-109.

LEFEBVRE, A. H. Atomization and sprays. New York Hemisphere Publishing Corporation, 1989. 421 p.

LUCHINI, L. C.; ANDRÉA, M. M. Comportamento ambiental de agroquímicos. Hortic. Bras., v. 18, p. 33-35, 2000. (Suplemento)

MATUO. T. Técnicas de aplicação de defensivos agrícolas. Jaboticabal: Funep, 1990. 139 p.

MATUO, T. et al. Tecnologia de aplicação e equipamentos. In: ABEAS - Curso de proteção de plantas. Módulo 2. Brasília: ABEAS; Viçosa, MG: UFV, 2001. 85 p. 
MILLER, P. C. H.; BUTLER ELLIS, M. C. Effects of formulation on spray nozzle performance for applications from ground-based boom sprayers. Crop Protec., v. 19, n. $8-10$, p. $609-615.2000$

QUEIROZ, A. A. et al. Adjuvantes e qualidade da água na aplicação de agrotóxicos. Biosci. J., v. 24, n. 4, p. 8-19, 2008.

SIDAHMED, M. M. Analytical comparison of force and energy balance methods for characterizing sprays from hydraulic nozzles. Trans. ASAE, v. 41, n. 3, p. 531-536, 1998.
STAINIER, C. et al. Droplet size spectra and drift effect of two phenmedipham formulations and four adjuvants mixtures. Crop Protec., v. 25, n. 12, p. 1238-1243, 2006.

THEBALDI, M. S. et al. Efeito da adição de adjuvante na redução de deriva em pontas de pulverização tipo cone vazio. R. Ci. Técnicas Agropec., v. 18, n. 2, p. 1-6, 2009.

VIANA, R. G. et al. Distribuição volumétrica e espectro de gotas de pontas pulverização de baixa deriva.

Planta Daninha, v. 28, n. 2, p. 439-446, 2010. 